\title{
Las series españolas en YouTube: comparativa de género sobre el fenómeno fan
}

\author{
M HCJ no 6 | Año 2015 \\ Artículo no 9 (70) \\ Páginas 219 a 240 \\ mhjournal.org
}

\author{
Tatiana Hidalgo Marí | tatianahidalgomari@gmail.com \\ Universidad de Alicante \\ Candelaria Sánchez Olmos| cande.sanchez@ua.es \\ Universidad de Alicante
}

Palabras clave

Fenómeno fan, ficción televisiva; género; redes sociales; YouTube

Sumario

1. Introducción

2. Marco teórico

3. La actividad de los fans o el feedback del usuario como herramienta de promoción 3.1. YouTube y la participación en clave de género a red

4. Diseño de la investigación. Investigation 4.1. Objetivos y preguntas de investigación 4.2. M etodología.

5. Resultados 5.1.Resultados acerca del tipo de contenido de los videos y el papel de la mujer en ellos.

6. Discusión y conclusiones
7. Notas
8. Bibliografía

\section{Resumen}

El presente trabajo analiza la actividad de la comunidad fan en Y ouTube en torno a las series televisivas de producción española a partir de un análisis comparativo de género.

Para ello, presentamos un estudio exploratorio a partir de una muestra basada en una metodología genuina, que recoge más de 100 vídeos subidos a Y ouTube por los fans y cuyo contenido es relativo a series españolas de estreno en 2013. Clasificamos los vídeos según el género y profundizamos en las unidades de registro a través de un análisis de contenido con el objetivo de observar qué papel tiene la mujer en el vídeo (protagonista, secundario o coral) y que relación guarda su rol con el género de quien sube el vídeo. Por otro lado, observamos qué tipo de vídeo suben hombres y mujeres con la finalidad de conocer quién es más creativo a la hora de expandir la narración de la ficción. Los resultados indican que los vídeos subidos por los hombres son ligeramente superiores en número a los subidos por las mujeres. Por otro lado, que los hombres son menos activos expandiendo el relato ficcional de las series porque aportan un mayor número de vídeos compuestos por escenas originales recortadas de las series. En las tres categorías de roles, principal secundario y coral, los hombres superan a las mujeres en la aportación de vídeos con representación de roles femeninos.

\section{Forma de citar este artículo en las bibliografías}

Tatiana Hidalgo Marí y Candelaria Sánchez Olmos (2015): “Las series españolas en YouTube: comparativa de género sobre el fenómeno fan”, en Miguel Hernández Communication Journal, n6, páginas 219 a 240. Universidad Miguel Hernández, UMH (Elche-Alicante). Recuperado el _- de de 20 de: [link del artículo en mhjournal.org] 


\section{The Spanish series on YouTube: gender comparative about fan phenomenon}

M HC) no 6 | Year 2015

Paper $\mathrm{n}$ 9 (70)

Pages 219 to 240

mhjournal.org

\author{
Tatiana Hidalgo Marí | tatianahidalgomari@gmail.com \\ Universidad de Alicante \\ Candelaria Sánchez Olmos| cande.sanchez@ua.es \\ Universidad de Alicante
}

Keywords

Fandom; TV fiction; gender; social media;

YouTube

Sumary

1. Introduction.

2. Theoretical Framework

3. The activity of the fans or the user feedback as a promotional tool 3.1. YouTube and gender participation in key network

4. Research design. 4.1 Investigation. Objectives and research questions. 4.2. Methodology.

5. Results 5.1.Resultados about the type of video content and the role of women in them

6. Conclusions

7. Notes

8. Bibliography

\section{Abstract}

This study explores YouTube users creation and consumption of videos related to Spanish TV series, from a gender perspective. The exploration is based on a sample of more than 100 short YouTube videos about 21 Spanish TV series premiered in 2013. These videos have been classified according to the gender of their up loaders.

On the other hand, we analyze the contents of the videos in order to see what role women have in the video (the protagonist, secondary or coral) and how it relates to their role gender that upload the video. Methodology is a quantitative analysis based on a date composed by videos from YouTube related with the 21 Spanish series premiered in 2013 in Spain. Research suggests interesting results. While men upload more videos, the videos created by women show greater production quality. Regarding the role of women in the video, men outnumber women uploading videos in which women occupy a leading role, secondary and coral.

\section{How to cite this paper in bibliographies}

Tatiana Hidalgo Marí and Candelaria Sánchez Olmos (2015): "The Spanish series on Youtube: gender comparative about fan phenomenon”, en Miguel Hernández Communication Journal, 끈, pages 219 to 240. Universidad Miguel Hernández, UMH (Elche-Alicante). Recuperado el __ de de 20 de: [link del artículo en

mhjournal.org] 


\section{Introducción}

La coexistencia de la televisión y las plataformas digitales, derivada del avance de la tecnología de la información y la comunicación, está generando nuevos paradigmas de comunicación, una nueva fase postmediática en la que las relaciones de los públicos con los medios en general y con la televisión en particular están cambiando: crece la fragmentación y se diluye la mediación (Campos Freire, 2008).

En un contexto comunicativo multimediático, multipantalla, deslocalizado y destemporizado, nos encontramos ante una audiencia fragmentada, exigente, rigurosa y sobre todo, activa, con voz y voto, capaz de detectar, analizar, criticar y, además, contribuir como si del mejor prescriptor del mundo se tratara, en la promoción virtual de los propios productos televisivos.

La figura del receptor, alejada ya de los modelos de comunicación lineales que imperaban en los años 20, ha cambiado radicalmente. La Teoría Funcionalista (Laswell, 1948; McLuhan, 1964; Wright 1960, entre otros) ya hablaba de la persuasión como el objetivo del paradigma comunicativo, capaz de despertar en el receptor esa ansia provocada, sobrevenida del propio mensaje, alejada de los paradigmas tradicionales de comunicación lineal. Pero fue Wiener (1958), coincidiendo con los orígenes de la cibernética, quien empezó a hablar de retroalimentación 0 feedback en el proceso comunicativo como la respuesta del receptor a ese estimulo persuasivo. En un contexto en red, en el que el receptor tiene voz y es capaz de actuar como sujeto activo sobre el mensaje, surge la nueva figura del prosumidor, un consumidor que también forma parte del proceso de producción del propio mensaje. El término, acuñado por Toffler en La tercera ola (1980), siguiendo las sugerencias de McLuhan y Nevitt (1972), sugiere que en un mercado de masas caracterizado por la estandarización (Horkheimer y Adorno, 1969) la estrategia de subsistencia recae en involucrar al consumidor en el diseño y la creación de los productos mediante una "mass customization" (Davis,1987). No obstante, el poder del receptor del producto masivo se ha visto desbordado con el auge de las redes sociales e Internet en general, dando lugar a un receptor-usuario de Internet que por una parte, puede ser partícipe de la creación de los mensajes y, en segundo lugar, es capaz de generar nuevos paratextos que sirven como instrumento promocional a la propia narrativa. Nos encontramos, pues, ante un receptorusuario que puede ser, a su vez, sujeto y creador de las propias narrativas transmediáticas.

Acercando ambas ideas al producto cultural de ficción, que es el que nos atañe en este trabajo, nos encontramos con que la audiencia, el receptor objeto de la ficción televisivo, se ha convertido en un prosumidor digital, ha sufrido una mutación y se ha convertido en un usuario cibernauta, gracias al auge de la Web 2.0 y, en especial, gracias a la participación derivada de las redes sociales que han incorporado nuevas herramientas y formas de interactividad que están estableciendo las lógicas de un nuevo espacio paradigma de comunicación Islas (2008: 20). 
El avance reside en la posibilidad por parte del prosumidor digital no solo en seleccionar, personalizar y consumir de forma individualizada el producto televisivo en cualquier soporte, sino que "el mensaje se mantiene en construcción permanente; y los públicos, frente a las narrativas mediáticas digitales, tienen la oportunidad de participar como sujetos de la acción" (Freitas y Castro, 2012: 29). Dicho de otro modo, el prosumidor tiene la capacidad de contribuir al desarrollo de los contendidos, mediante la generación de nuevos textos que sirven como paratextos de los textos madre, que contribuyen a la promoción de los mismos gracias a su distribución libre a través de las redes sociales.

En un contexto tecnológico en el que el feedback es la característica fundamental los recursos web, es necesario mencionar que la capacidad del usuario digital de generar nuevos paratextos que se convierten en narrativas transmediáticas que sirvan como promoción de la propia narración original, es una de las herramientas más fuertes a la hora de fomentar el consumo del producto cultural. El producto televisivo se convierte, pues, en una narrativa transmediática en tanto en cuanto es reproducida íntegramente en las plataformas de Internet. Pero no solo a través de las propias webs de las cadenas y otros recursos digitales que explotan el texto como paratexto digital en sus portales y archivos online, sino a través de otros soportes, redes sociales, blogs, etc. En las que se difunden paratextos creados por los propios usuarios, las propias audiencias de los productos de ficción, contribuyendo aun más a la explotación transmediática de las narrativas televisivas.

Nos encontramos por tanto, con que con el desarrollo tecnológico y el auge de la web 2.0, la figura del prosumidor se convierte en un sujeto estratégico no solo en la generación de contenido, sino también en su contribución a la retroalimentación de los mismos y a su promoción. Convirtiendo sus aportaciones en nuevas producciones, nuevas narrativas transtextuales pero también transmediáticas y que sirven como producto de consumo de otros usuarios con intereses similares. Se contribuye, por una parte, al fenómeno fandom (Baym, 1998; Jenkins 2009; González-Alarcón y Anyó 2009; Tous y Díaz, 2009) y se genera un espectáculo audiovisual online en el que la inteligencia colectiva, la "cosmopedia" Pierre Lévy (1997) es el sustento del proceso comunicativo y la que altera los procesos de producción y recepción de contenido cultural.

El trabajo que exponemos forma parte de una investigación más amplia cuyo objetivo principal es conocer la contribución promocional de los fans de las ficciones televisivas mediante la creación de nuevos textos, subidos a la red y compartidos públicamente entorno a la ficción. Para ello, se ha llevado a cabo una recopilación exhaustiva de materiales subidos a Y ouTube por parte de los fans de las ficciones objeto de estudio y se han medido los parámetros de tráficos web e interacción de los desde una perspectiva comparativa de género, con el objetivo de conocer las diferencias entre hombres y mujeres a la hora de contribuir, mediante la generación de videos subidos y materiales volcados a la red social YouTube. Como colofón, y en un intento por seguir la línea comparativa entre géneros, se ha analizado el papel de la mujer dentro de los videos 
subidos por parte de los fans, con el objetivo de detectar vinculaciones de género y diferencias fundamentales en la construcción social de la mujer dentro de los contenidos de los propios fans.

\section{Marco teórico: narrativas transmediáticas en marcos de ficción 2.0}

Partiendo de la premisa de que todo texto es un paratexto que se nutre de un texto anterior (Barthes, 2002) entendemos que las narrativas transmediáticas son el contenido narrativo que aúna estos paratextos, la sustancia común, la esencia narrativa que permite entender todos los paratextos como parte de una misma narrativa. Si hablamos de narrativas transmediáticas, en el contexto de la ficción televisiva, podemos decir que:

Esta "diseminación sistemática" en diversos medios y canales contribuye a la generación de un panorama narrativo alrededor de una narración que genera partes interconectadas de un todo que responde a la propia naturaleza de la narración. Los públicos, fanso aficionados a dicha narración sienten la necesidad de profundizar en cada uno de los contendidos, convirtiéndose en "usuarios transmediales" (Scolari, 2009: 597) que no son más que fans empedernidos alrededor del fenómeno narrativo.

Pero no podemos obviar que el fenómeno transmediático va más allá de la reproducción en multiplataformas puramente dicha, sin una extensión evidente de la narración -lo que denominaríamos un fenómem aossmedia, (Beeson, 2005; D avidson, 2008; Scolari, 2009; Hernández y G randío, 2011)- para dar lugar a nuevos textos que innovan frente al relato de origen y aportan nuevas consideraciones que no adquieren sentido si no son entendidas como partes de un "todo" narrativo. Las series se reproducen, íntegramente, en plataformas online de las propias productoras o a través de canales específicos, haciendo referencia a un fenómemo crossmedia, pero lo que realmente no atañe es la existencia de nuevas narrativas que, lejos de ser reproducciones totales o parciales del texto de origen, aportan nuevos sentidos, otras lecturas o efectos promocionales al texto fuente, en otras plataformas.

Son muchos los estudios que se han centrado en el estudio del transmedia staytellingcomo fórmula comunicativa en el nuevo contexto en red (Rodríguez, 2012; Guerrero, 2012; Scolari, Jiménez y Guerrero, 2012; Tognazzi, 2012; Rojas, 2013;), pero estos estudios obvian, en muchas ocasiones, la importancia de la contribución que genera el propio usuario, el propio receptor del mensaje, la figura tradicionalmente pasiva que ahora es un sujeto activo del paradigma comunicativo, un fan con voz en el transcurso discursivo del propio producto. En el campo de la ficción televisiva, la actividad del usuario en los distintos medios online, retroalimenta los productos televisivos, generando mucho tráfico alrededor de estos. Este usuario se convierte en creador activo de las nuevas narrativas transmediáticas que acompañan, de forma paratextual, a los textos-fuente, generando relaciones que ahora es creador de nuevos paratextos que sirven como elementos de promoción de los textos-fuente genera relaciones "casi simbióticas" (Lacalle, 2011) entre la ficción televisiva y las nuevas tecnologías. Ferreras (2011: 2) afirma que "las cifras de usuarios de las redes sociales son elevadas, los flujos publicitarios han migrado hacia estos ambientes y 
muchos contenidos antes ofrecidos por los medios se han trasladado a las redes sociales". Y es que las redes sociales dan pie a esa generación de nuevos contenidos que aporten valor promocional a los productos televisivos en sí y de los que el usuario es el autor directo.

Como explica Scolari (2009) en su análisis descriptivo de la estructura de textos multimedia, el concepto de transmedia starytdling (citando a Jenkins, 2009) en un nivel esencial se definiría mediante historias contadas a través de diferentes medios. Para Scolari, en la actualidad el concepto ha evolucionado y los textos tienden a fluir a través de múltiples plataformas, de tal manera que la transmedialidad no solo afecta al texto, sino que además incluye transformaciones en la producción y en el consumo.

"Transmedia storytelling is a narrative that includes a series of stories expressed through different media. This narrative articulates an expression (TV serials, comics, video games, etc) with a hierarchy of values that act as the content of the fictional world. These values are expressed in all the different texts that integrate the space of a certain transmediastorytelling experience" (Scolari, 2009: 600).

Ahora bien, el tema que nos ocupa da un paso más y pretende aunar en la capacidad de los propios fans miembros de comunidades online vinculadas a las ficciones y seguidores fieles de los contenidos virtuales de estas, para generar nuevos textos en Internet que sirvan como promoción de la propia ficción. En este sentido, nos encontramos ante un proceso de "transformación del producto" y a su vez de "transformación del consumo" siguiendo las afirmaciones de Scolari. En este sentido, el receptor ya no se conforma con ser un mero espectador, sino que quiere ser partícipe del proceso, contribuyendo así a la retroalimentación transmediática del propio producto de ficción. (Gabelas, 2005; Guarinos, 2009).

\section{La actividad de los fans o el feedback del usuario como herramienta de promoción}

Q ue Internet ha revolucionado la comunicación y sus procesos es una realidad innegable. En esta vorágine comunicativa, la web 2.0 "materializa el ideal de la retroalimentación y convierte los monólogos en diálogos, al incorporarse el feedbadk del destinatario en el proceso de comunicación de masas" (Lacalle, 2010: 65). El usuario, receptor de los contenidos televisivos puede configurar y organizar su propio consumo televisivo a través de nuevas plataformas y además, tiene la posibilidad de "diseñar su propia parrilla de programación y experimentar su nueva faceta como productor-distribuidor de sus propios contenidos por Internet" (Rosique, 2009: 147). Este hecho tiene como consecuencia la revolución de los medios sociales, en los que la actividad del usuario/ internauta, juega un papel fundamental así como la conversión de Internet en un núcleo de negocio por pare de los grandes holdings televisivos (Guerrero 2011:100). Los usuarios, según afirma Jenkins hablando de esta nueva convegenia mediática: "se vuelven cazadores y recolectores, agrupando la información de múltiples fuentes para formar una nueva síntesis" (2009: 46). 
Nos encontramos, pues, con un espacio digital en el que las ficción televisiva "se revitaliza a través de los múltiples recursos ofrecidos en la web" (Lacalle 2013: 174) aunque esta nueva configuración del espacio de consumo digital "no radica tanto en su capacidad funcional, como en la representación mediática de los objetivos de sus instituciones o empresas (Victoria y Arjona, 2009: 70). Pero también debemos tener en cuenta el proceso inverso, en el que Internet se nutre de las narrativas audiovisuales televisivas, en este caso, de la propia ficción, completando así el flujo de las narrativas transmediáticas (Jenkins, 2006) aunque sería más coherente hablar de hablar de "transmedia engagement (Evans, 2011; Lacalle 2013:174), que comprende las relaciones de los espectadores con el programa a través de los distintos recursos web.

El discurso de los fans, incrementa el consumo televisivo al diseminar de manera remota los comentarios sobre programas de televisión entre amigos, familiares y desconocidos. (D eloitte 2012), convirtiéndose, pues, en una herramienta de distribución tanto dentro de la comunidad fan como fuera de ésta. Además, no podemos obviar que el feedbadk de los usuarios representa un factor de soial empowement (Borrelli, 2008:15) para un espectador relegado tradicionalmente al papel de mero receptor.

El estudio sobre la audiencia-fan y su alcance como promotora del éxito de la ficción en Internet, es un tema que empieza a suscitar mucho interés tanto para anunciantes como para productoras y televisiones. Aunque el fenómeno fan y la interactividad de la audiencia está suscitando mucho interés en el ámbito académico, resulta destacable que no existe una clasificación formal de las mismas, aunque algunos estudios empiezan a abordar la repercusión de la actividad de los fans alrededor de la ficción televisiva (Lacalle, 2011; Hernández y Grandío, 2011; Tur y Rodríguez, 2013).

Fiske (1992) ya estableció que el estudio de la comunidad fan debe hacerse desde la producción y no desde la recepción. Los fans son los productores de una cultura alternativa con gran carga narrativa pero también semiótica. Los valores que los fans aplican a sus productos tiene el mismo valor que el del texto base, por ese motivo, es necesario concebir a la comunidad fan como un sujeto activo dentro del proceso de construcción de las narrativas transmediáticas.

Hernández y G randío (2011), en un estudio sobre el fenómeno fan alrededor de la ciencia ficción disemina los distintos tipos de consumidores dentro de la propia comunidad fan y destaca la figura del consumidor transmedial, definiéndolo como: "El consumidor más interesado en el mundo ficcional propuesto y se adentra en los diferentes lenguajes que constituyen el macrorelato. Es el usuario más completo y que se relacionaría con el fenómeno fan más acérrimo" (2011: 15). Este tipo de fan es el que más nos interesa para nuestro trabajo puesto que es el que muestra mayor grado de implicación en la promoción, creación y distribución tanto del propio contenido de las narrativas transmediátcas de la ficción como en el desarrollo contenido innovador y genuino para ser distribuido en Internet, generado por la propia comunidad fan. 


\subsection{YouTube y la participación en clave de género a red}

Que Internet ha revolucionado la comunicación y sus procesos es una realidad innegable. En esta vorágine comunicativa, la web 2.0 "materializa el ideal de la retroalimentación y convierte los monólogos en diálogos, al incorporarse el feedback del destinatario en el proceso de comunicación de masas" (Lacalle, 2010: 65). El usuario, receptor de los contenidos televisivos puede configurar y organizar su propio consumo televisivo a través de nuevas plataformas y además, tiene la posibilidad de "diseñar su propia parrilla de programación y experimentar su nueva faceta como productor-distribuidor de sus propios contenidos por Internet" (Rosique, 2009: 147). Este hecho tiene como consecuencia la revolución de los medios sociales, en los que la actividad del usuario/ internauta, juega un papel fundamental así como la conversión de Internet en un núcleo de negocio por pare de los grandes holdings televisivos (Guerrero 2011:100). Los usuarios, según afirma Jenkins hablando de esta nueva convergencia mediática: "se vuelven cazadores y recolectores, agrupando la información de múltiples fuentes para formar una nueva síntesis" (2009: 46).

Nos encontramos, pues, con un espacio digital en el que las ficción televisiva "se revitaliza a través de los múltiples recursos ofrecidos en la web" (Lacalle 2013: 174) aunque esta nueva configuración del espacio de consumo digital "no radica tanto en su capacidad funcional, como en la representación mediática de los objetivos de sus instituciones o empresas (Victoria y Arjona, 2009: 70). Pero también debemos tener en cuenta el proceso inverso, en el que Internet se nutre de las narrativas audiovisuales televisivas, en este caso, de la propia ficción, completando así el flujo de las narrativas transmediáticas (Jenkins, 2006) aunque sería más coherente hablar de hablar de "transmedia engagement (Evans, 2011; Lacalle 2013:174), que comprende las relaciones de los espectadores con el programa a través de los distintos recursos web.

El discurso de los fans, incrementa el consumo televisivo al diseminar de manera remota los comentarios sobre programas de televisión entre amigos, familiares y desconocidos. (D eloitte 2012), convirtiéndose, pues, en una herramienta de distribución tanto dentro de la comunidad fan como fuera de ésta. Además, no podemos obviar que el feedback de los usuarios representa un factor de social empowerment (Borrelli, 2008:15) para un espectador relegado tradicionalmente al papel de mero receptor.

El estudio sobre la audiencia-fan y su alcance como promotora del éxito de la ficción en Internet, es un tema que empieza a suscitar mucho interés tanto para anunciantes como para productoras y televisiones. Aunque el fenómeno fan y la interactividad de la audiencia está suscitando mucho interés en el ámbito académico, resulta destacable que no existe una clasificación formal de las mismas, aunque algunos estudios empiezan a abordar la repercusión de la actividad de los fans alrededor de la ficción televisiva (Lacalle, 2011; Hernández y Grandío, 2011; Tur y Rodríguez, 2013). 
Fiske (1992) ya estableció que el estudio de la comunidad fan debe hacerse desde la producción y no desde la recepción. Los fans son los productores de una cultura alternativa con gran carga narrativa pero también semiótica. Los valores que los fans aplican a sus productos tiene el mismo valor que el del texto base, por ese motivo, es necesario concebir a la comunidad fan como un sujeto activo dentro del proceso de construcción de las narrativas transmediáticas.

Hernández y G randío (2011), en un estudio sobre el fenómeno fan alrededor de la ciencia ficción disemina los distintos tipos de consumidores dentro de la propia comunidad fan y destaca la figura del consumidor transmedial, definiéndolo como: "El consumidor más interesado en el mundo ficcional propuesto y se adentra en los diferentes lenguajes que constituyen el macrorelato. Es el usuario más completo y que se relacionaría con el fenómeno fan más acérrimo" (2011: 15). Este tipo de fan es el que más nos interesa para nuestro trabajo puesto que es el que muestra mayor grado de implicación en la promoción, creación y distribución tanto del propio contenido de las narrativas transmediátcas de la ficción como en el desarrollo contenido innovador y genuino para ser distribuido en Internet, generado por la propia comunidad fan.

\section{Diseño de la investigación}

En el campo de la transmedialidad narrativa, destacan los estudios de Scolari (2009) aunque son muchos los autores que han analizado este fenómeno narrativo (Rodríguez, 2012; Guerrero, 2012; Scolari, Jiménez y G uerrero, 2012; Tognazzi, 2012; Rojas, 2013), tanto dentro de la ficción como fuera de ella. El estado de la cuestión en relación a los estudios sobre feedbadk y retroalimentación se centran en estudios de audiencias en Internet, aunque recientemente han visto la luz resultados de investigación que se centran en el estudios de la actividad de los usuarios en redes sociales e Internet (Lacalle, 2011; Lacalle, 2013).

Nuestro trabajo aporta un carácter innovador a estos campos de conocimiento en tanto en cuanto analiza el papel de los fans - a su vez, usuarios de Internet y redes sociales- y el carácter transmediático de sus contribuciones. Además, el diseño de la investigación adquiere una nueva dimensión original en el momento en que planteamos el estudio comparativo de género, con el fin de indagar un poco más acerca de las diferencias fundamentales de contribución de los fans en función del género.

D estacar que los estudios sobre la construcción social de la mujer han sido un tema recurrente desde siempre y en especial, a partir de los años 80, momento en el que se establecían que los discursos televisivos ejercen un papel fundamental en la representación y transmisión de roles sociales (G erbner et al., 1980; Gerbner, 1998; Lauzen, D ozier y Horan, 2008; Glascock, 2001). Son muchos los estudios que han recaído en la construcción social de la mujer a través de la televisión, aunque muy pocos se han centrado en el papel de la mujer como sujeto capaz de generar feedbadk social y feedbadk de contenido. Mujeres y hombres interactúan en las comunidades fan pero consideramos que merece la pena empezar a establecer las diferencias fundamentales en dicha interacción. Este hecho supone un punto más a favor del trabajo, que pretende aportar una 
nueva visión comparativa de género a los estudios sobre usabilidad y participación de los usuarios de Internet y las redes sociales.

\subsection{Objetivos y preguntas de investigación.}

El estudio que presentamos pretende describir, analizar y valorar el tráfico generado por los fans en YouTube alrededor de las series televisivas de producción nacional, desde un punto de vista comparativo entre mujeres y hombres. El objetivo es establecer las diferencias fundamentales entre la actividad de unos y otros dentro de la propia comunidad fan. Además, se pretende examinar la relación existente entre la mayor o menor actividad interactiva por parte de mujeres y hombres y el tráfico que generan sus contribuciones. Los objetivos de este trabajo son, por tanto, los siguientes:

a) Conocer la actividad transmediática que aportan los fans a la ficción televisiva española, mediante su contribución a la red social Y ouTube, describiéndolos desde una comparativa entre hombres y mujeres.

b) Conocer y comparar por género cómo son los vídeos que suben hombres y mujeres observando si son imágenes originales de las serie o videocreaciones propias de los fans.

c) Profundizar en los contenidos de los videos, para observar el papel que ocupa la mujer en el video (protagonista, secundario o coral) y qué relación guarda su rol con el género de quien sube el vídeo.

Para poder profundizar y dar respuesta a estos tres objetivos fundamentales, se plantean las siguientes preguntas de investigación: ¿Existen diferencias en el volumen de participación entre hombres y mujeres dentro de la comunidad fan alrededor de la ficción televisiva? ¿Q ué tipo de imágenes contienen los vídeos subidos por los fans? Y en tercer lugar: ¿Q ué papel ocupa la mujer en los videos subidos y qué relación existe entre este rol y el género de quien sube el video?

\subsection{Metodología}

La muestra en la que se basa el estudio exploratorio está compuesta por las 21 series de televisión españolas de estreno emitidas durante 2013 en canales de ámbito nacional con el fin de poder analizar la existencia en YouTube de vídeos relativos a las series de televisión subidos por usuarios particulares, centrándose en la participación de las usuarias de la red social, tanto en el protagonismo femenino como sujeto que sube el video en el contenido de estos videos y el tráfico que generan. La muestra de análisis tiene como fuente matriz las siguientes series: 
Tabla 1: M atriz de series a analizadas

\begin{tabular}{|c|c|c|c|c|c|}
\hline Título & Cadena & Año estreno & $\begin{array}{c}\text { Temporad } \\
\text { a } 2013\end{array}$ & $\begin{array}{c}\text { Share } \\
\text { (media 2013) }\end{array}$ & $\begin{array}{l}\text { Espectadores } \\
\text { (media 2013) }\end{array}$ \\
\hline $\begin{array}{l}\text { Cuéntame cómo } \\
\text { pasó }\end{array}$ & TVE1 & 2001 & $14^{\mathrm{a}}$ & $20.49 \%$ & 4.101 .750 \\
\hline Gran Reserva & TVE1 & $\begin{array}{c}2010 \\
\text { (finalizada) }\end{array}$ & $3^{\mathrm{a}}$ & $13,46 \%$ & 2.771 .375 \\
\hline $\begin{array}{l}\text { Gran Reserva. El } \\
\text { origen }\end{array}$ & TVE1 & $\begin{array}{c}2013 \\
\text { (finalizada) }\end{array}$ & $1^{\mathrm{a}}$ & $7,53 \%$ & 881.744 \\
\hline Isabel & TVE1 & 2012 & $2^{-\underline{a}}$ & $16,80 \%$ & 3.350 .692 \\
\hline Águila roja & TVE1 & 2009 & $5^{\mathrm{a}}$ & $23.38 \%$ & 4.469 .333 \\
\hline $\begin{array}{l}\text { Amar es para } \\
\text { siempre }\end{array}$ & A3 & 2013 & $1^{\frac{a}{-}-2^{a}}$ & $13,62 \%$ & 1.686 .609 \\
\hline El barco & A3 & $\begin{array}{c}2011 \\
\text { (finalizada) }\end{array}$ & $3^{a}$ & $12,60 \%$ & 2.264 .333 \\
\hline $\begin{array}{lr}\text { El secreto } & \text { de } \\
\text { Puente viejo } & \end{array}$ & A3 & 2011 & $2^{\mathrm{a}}-3^{\mathrm{a}}$ & $17,32 \%$ & 1.959 .011 \\
\hline Fenómenos & A3 & $\begin{array}{c}2012 \\
\text { (finalizada) }\end{array}$ & $1^{\mathrm{a}}$ & $12,74 \%$ & 2.339 .111 \\
\hline Con el culo al aire & A3 & 2012 & $2^{\underline{a}}$ & $17,02 \%$ & 3.039 .231 \\
\hline Bandolera & A3 & $\begin{array}{c}2011 \\
\text { (finalizada) }\end{array}$ & $2^{\mathrm{a}}$ & $12,83 \%$ & 1.681 .000 \\
\hline $\begin{array}{l}\text { Luna, el misterio } \\
\text { de Calenda }\end{array}$ & A3 & $\begin{array}{c}2012 \\
\text { (finalizada) }\end{array}$ & $2^{\mathrm{a}}$ & $12,87 \%$ & 2.288 .143 \\
\hline Gran Hotel & A3 & $\begin{array}{c}2011 \\
\text { (finalizada) }\end{array}$ & $3^{\mathrm{a}}$ & $13,98 \%$ & 2.636 .952 \\
\hline Vive cantando & A3 & 2013 & $1^{\mathrm{a}}$ & $15,19 \%$ & 2.614 .643 \\
\hline $\begin{array}{l}\text { El tiempo entre } \\
\text { costuras }\end{array}$ & A3 & $\begin{array}{c}2013 \\
\text { (finalizada) }\end{array}$ & $1^{\mathrm{a}}$ & $25,27 \%$ & 4.828 .556 \\
\hline Aída & T5 & 2005 & $10^{\mathrm{a}}$ & $14,41 \%$ & 2.690 .833 \\
\hline La que se avecina & T5 & 2007 & $6^{\frac{a}{a}-7^{a}}$ & $21,79 \%$ & 4.181 .000 \\
\hline Frágiles & T5 & $\begin{array}{c}2012 \\
\text { (finalizada) }\end{array}$ & $2^{\underline{a}}$ & $10,03 \%$ & 1.278 .625 \\
\hline
\end{tabular}




\begin{tabular}{|l|c|c|c|c|c|}
\hline Familia & T5 & $\begin{array}{c}2013 \\
\text { (finalizada) }\end{array}$ & $1^{\underline{a}}$ & $11,93 \%$ & 2.121 .375 \\
\hline Tierra de lobos & T5 & 2010 & $3^{\underline{a}}$ & $12,40 \%$ & 2.078 .846 \\
\hline El don de Alba & T5 & $\begin{array}{c}2013 \\
\text { (finalizada) }\end{array}$ & $1^{\underline{a}}$ & $8,94 \%$ & 1.571 .917 \\
\hline
\end{tabular}

Fuente: Elaboración propia a partir de IMDB y Formula TV

La metodología seguida para la recogida del muestreo se ha basado en el filtro "Relevancia" que ofrece YouTube y en el filtro de corta duración de YouTube (menos de 4 minutos según posibilidades de filtrado que ofrece la red social) relativos a las series españolas de estreno en 2013, en total 21 series de cadenas generalistas de cobertura estatal. La selección de la muestra se realizó del 21 al 27 de julio de 2014. El criterio "relevancia" tiene en cuenta el número de visualizaciones, el engagement que ha suscitado el vídeo (número de veces en que el vídeo ha sido elegido como favorito por los usuarios, número de likes y de comentarios), el tiempo de vídeo reproducido y si la pieza ha sido subida desde una cuenta que goza de antigüedad, así como la actividad del mismo. El filtro de YouTube por lo tanto ofrece estabilidad temporal a la muestra porque el posicionamiento de vídeos no depende únicamente de las visualizaciones sino de otros factores que hemos indicado.

De esta selección obtenemos 314 vídeos de los cuales solo se han tenido en cuenta para esta investigación los videos en los 127 que nos permiten identificar el género del sujeto que lo sube a la red y atendiendo al nombre que cada usuario indica en el canal. Por consiguiente, eliminamos los videos trabajados subidos por las propias cadenas y/ productoras puesto que no tienen adscripción de género. Además, se hace especial hincapié en la recogida de material amateur e inédito, creados por usuarios, puesto que son los materiales que, realmente, evidencian la contribución promocional de los usuarios a la ficción. Esta exclusividad buscada en la recogida de datos supone, al fin y al cabo, el poder trabajar con contenidos ciertamente trasmediáticos, que aporten desarrollos narrativos novedosos, en forma de microhistorias intersticiales, historias paralelas, historias periféricas (Scolari, 2009).

Una vez hemos seleccionado la muestra aplicamos un análisis de contenido a los 127 vídeos 0 unidades de registro. El análisis de contenido es la técnica más elaborada y la que goza de mayor prestigio científico en el campo de la observación documental (Sierra y Bravo, 1994). El análisis de contenido es, según Berelson, "una técnica de investigación para la descripción objetiva, sistemática y cuantitativa del contenido manifiesto de las comunicaciones, con el fin de interpretarlas" (citado por Sierra Bravo, 1994: 286). La razón por la cual nos hemos decantado por esta metodología es porque, tal y como indicó Krippendorff (1990: 10), "el análisis de contenido tiene una orientación fundamentalmente empírica, exploratoria, vinculada a fenómenos reales y de finalidad predictiva". Con el objetivo de explorar el fenómeno fan en YouTube, hemos aplicado a las 127 unidades de registro diferentes variables con sus correspondientes categorías. La primera variable tiene como objetivo conocer que género aportas 
más videos relacionados con las series a YouTube. La segunda variable tiene como objetivo conocer qué tipo de vídeos suben los fans de las series a YouTube. Para ello establecemos seis categorías: 1.Imágenes originales de la serie, 2.Imágenes animadas, 3. Grabación casera, 4.Mezcla serie / caseras, 5. Sin imagen, 6. Otro. Por último, en la tercera variable analizamos el papel de la mujer dentro del video. Para ello también establecemos tres categorías: 1. Principal, 2. Segundario, 3., Coral.

\section{Resultados}

Tras la recogida de datos siguiendo los criterios metodológicos y la clasificación de todos los registros muestrales en un documento matriz, se obtienen los siguientes datos generales:

Tabla 2: Videos subidos por género

\begin{tabular}{|c|c|}
\hline & Total videos subidos por género \\
\hline MUJERES & $56(44 \%)$ \\
\hline HOMBRES & $71(56 \%)$ \\
\hline TOTAL & $127(100 \%)$ \\
\hline
\end{tabular}

Fuente: Elaboración propia basada en los resultados de la recogida de la muestra

Como se puede observar, tras la aplicación de la metodología a la recogida de la muestra, nos encontramos con que existen un total de 127 videos que responden a las necesidades de la investigación. De esta muestra final, el 44\% de los videos han sido subidos por mujeres (56 piezas en total) frente al $56 \%$ del total, que han sido subidos por hombres (71 piezas). Este dato nos permite afirmar, a priori, que la actividad de los fans masculinos en la red social YouTube alrededor de la ficción televisiva es mayor que la de las mujeres. A pesar de la evidencia inicial, no podemos obviar que la diferencia porcentual no es extrema, ya que solo existen un $12 \%$ más de casos atribuidos a los hombres, frente a los que se atribuyen a mujeres.

Siguiendo con los objetivos planteados, observamos las diferencias en la media de las visualizaciones de los videos subidos por ellos y ellas: 34.632 hombres vs. 30.147 visualizaciones de las mujeres (Tabla 3). En este caso, en términos absolutos, los hombres obtendrían mayor media de visualizaciones que las mujeres.

Ahora bien, dado que no podemos suponer normalidad ni homogeneidad de varianzas, utilizamos la prueba no paramétrica U de Mann-Whitney con la finalidad de conocer si estos resultados se pueden extrapolar a toda la población. El test contrasta si las medianas del número de visualizaciones son iguales para mujeres y hombres o si por el contrario son distintas. Al obtener un p-valor (Sig. asintótico) de 0,149 mayor que 0,05 no podemos afirmar, en términos estadísticos, que la media de los vídeos subidos por mujeres sea distinta a la media de visualizaciones obtenidas por los hombres ni viceversa. Por lo tanto, para la muestra que 
presentamos los hombres superan a las mujeres en media de visualizaciones sin embargo, estos resultados no pueden ser extrapolados a toda la población.

\subsection{Resultados acerca del tipo de contenido de los videos y el papel de la mujer en ellos.}

Con el fin de acercarnos a las diferencias narrativas que presentan los contenidos subidos por hombres y mujeres entorno a la ficción, se han clasificado los registros muestrales en función del tipo de imagen que contienen y los resultados son los siguientes:

Tabla 3: Tipo de imágenes de los videos

\begin{tabular}{|c|c|c|c|c|c|c|r|}
\hline \multicolumn{7}{|c|}{ Tipo de imágenes de los videos } \\
\hline & $\begin{array}{c}\text { Imágenes } \\
\text { originales } \\
\text { de la } \\
\text { serie }\end{array}$ & $\begin{array}{c}\text { Imágenes } \\
\text { animadas }\end{array}$ & $\begin{array}{c}\text { Grabación } \\
\text { casera }\end{array}$ & $\begin{array}{c}\text { Mezcla } \\
\text { serie } \\
\text { /caseras }\end{array}$ & $\begin{array}{c}\text { Sin } \\
\text { imagen }\end{array}$ & Otro & TOTAL \\
\hline MUJERES & 29 & 1 & 7 & 3 & 1 & 15 & $\mathbf{5 6}$ \\
\hline HOMBRES & 40 & 1 & 7 & 10 & 1 & 12 & $\mathbf{7 0}$ \\
\hline TOTAL & 69 & 2 & 14 & 13 & 2 & 27 & $\mathbf{1 2 7}$ \\
\hline
\end{tabular}

Fuente: Elaboración propia

Como podemos observar, en términos absolutos, las difenencias más significativas residen en el uso de imágenes originales de la serie, caso en el que los hombres generan una aportación significativamente superior a la de las mujeres. Esto implica que el comportamiento de los fans masculinos en Internet se basa mayoritariamente en "cortar" escenas de las series y subirlas a YouTube, lo que indica que no existe una contribución real a la expansión del relato por otra plataforma. En la categoría "grabación casera", que se refieren a los contenidos que incluyen una grabación amateur por parte de los usuarios, hombres y mujeres aportan los mismos vídeos (7 y 7) lo que confirma la escasa expansión de la ficción. Los hombres, además, se muestran más interactivos a la hora de generar videos que combinen imágenes caseras con imágenes reales de la propia ficción, estrategia de creación que, según los datos, no atrae demasiado a las mujeres fans. Las mujeres solo se muestran más interactivas en la creación de otro tipo de videos, entre los que destacan la superposición de varias imágenes de la serie con una canción que, en ocasiones, coincide con las banda sonora de la serie. Este dato nos permite suponer que las mujeres se muestran más creativas en la aportación de contenidos más originales que los hombres.

En cualquier caso, y dado que no ponemos suponer homogeneidad en los datos obtenidos, se ha aplicado el test Chi-cuadrado de Pearson, que nos da un p-valor (Sig. asintótica) de 0,207 > 0,05 por lo que no podemos afirmar que exista asociación entre el género y el tipo de imagen. No podemos afirmar, pues, que los hombres suban más vídeos con imágenes originales de las series y las mujeres más videos con imagen videográfica. 
Con la finalidad de describir el tipo de vídeos que los fans han subido a Y ouTube describimos algunos de los vídeos más significativos subidos por ellas y ellos desde una perspectiva cualitativa. En cuento a ellas, el canal 4lakegirl (30.697 visitas, 628 suscriptores) hace su propio tráiler de la serie Ágila Rga, de una manera muy profesional. O tra fan, Malu Romero (40.098 visitas, 4.422 suscriptores), crea un display de fotos fijas de la serie Gran Reserva, con cuadros de diálogo presentando a los personajes y diciendo qué actores los interpretan. Ainhoa Leiva González (7.486 visitas, 286 suscriptores) sube un display de fotos, acompañadas de una cabecera y un cierre originales, para presentar a los actores de la serie de Antena 3 Vive cantando , que se había estrenado el día anterior. Cada foto incluye un rótulo con el nombre del actor y del personaje, y la música que se escucha es "Mirrors", de Justin Timberlake. En cuanto a ellos, tenemos también un v-log con una crítica de la serie El don deAlba2, donde el fan sostiene que es una copia de Entre fantasmas. Otro fan, @joseSL9, hace dos cabeceras alternativas a la de la serie Gran Resva, virando al blanco y negro y al color vino planos de la serie, con fundidos y sobreimpresiones. Estos son algunos de los ejemplos que muestran la creatividad de los fans.

El último bloque de resultados nos indica datos en relación al papel que ocupa la figura de la mujer dentro del video. Este análisis se ha llevado a cabo con la intención de establecer de qué manera se representan las mujeres a ellas mismas y de qué forma son representadas en los videos que suben los hombres a la red social. Los datos recopilados de la investigación son los siguientes:

Tabla 4: Papel de la mujer dentro del video

\begin{tabular}{|c|r|r|r|r|}
\hline \multicolumn{5}{|c|}{ PAPEL DE LA MUJER DENTRO DEL VIDEO } \\
\hline & \multicolumn{1}{|c|}{ Principal } & Secundario & Coral & TOTAL \\
\hline \multirow{2}{*}{ MUJERES } & 21 & 4 & 19 & 44 \\
& $21,2 \%$ & $4,0 \%$ & $19,2 \%$ & 54 \\
HOMBRES & 27 & 7 & 20 & 98 \\
\hline TOTAL & $28,3 \%$ & $7,1 \%$ & $20,2 \%$ & \\
\hline
\end{tabular}

Fuente: Elaboración propia

Observamos que existe bastante equilibrio a la hora de representar a la mujer dentro de los videos. Tanto a la hora de representar personajes femeninos principales como con protagonismo coral y no existe demasiada varianza entre ambos. En las tres categorías, principal secundario y coral, los hombres superan a las mujeres en la representación de los roles femeninos. Ahora bien, tras la aplicación del test Chi-cuadrado de Pearson obtenemos un p-valor (Sig. asintótica) de $0,748>0,05$ por lo que no podemos afirmar que exista asociación entre el género y el papel de la mujer dentro del vídeo ni podemos afirmar que las mujeres suban más vídeos en los cuales tienen estas un papel principal. Estos datos, por tanto, nos permiten afirmar que el protagonismo de la 
mujer en los videos no depende en ningún caso del género del fan que suba el video, puesto que no existe una correlación positiva de datos. Así pues, nos permite confirmar que, a la hora de subir videos a YouTube, la comunidad fan se centra en el contenido puramente ficcional, es decir, se trabajan los contenidos alrededor de los intereses de la ficción pero, a priori, no parece que exista una intención narrativa que afecte a la construcción social de los sujetos.

\section{Discusión y conclusiones}

El estudio comparativo entre hombres y mujeres ha permitido constatar, además, que la contribución de los hombres a la transmedialidad de las ficciones en Y ouTube es mayor que la de las mujeres, en términos absolutos. Esta afirmación fundamental se opone a conclusiones en investigaciones sobre espectadores jóvenes diseminadas por género, que hablaban de la tendencia participativa de los hombres en los productos televisivos deportivos frente al decante femenino por el producto de ficción (Sandoval, 2006; Medrano, 2007; G uarinós, G ordillo y Ramírez, 2010). Estos datos, que hacían referencia únicamente al visionado de producto televisivo en Internet nos sirven de argumento para confirmar que, a pesar de que la figura masculina está vinculada a otros productos y temáticas culturales, lo cierto es que es evidente la vinculación y la implicación de los hombres ante la promoción de la ficción muy potente de los hombres frente a las mujeres.

Los resultados obtenidos en este trabajo nos indican que es conveniente ampliar la investigación relacionada con la interacción y el género, ya sea desde una perspectiva cualitativa o cuantitativa, o bien con una combinación de ambas. Tal y como expone Pierson (2015), las causas que justifican la diferencia entre la interacción masculina y la femenina no son fáciles de explicar y responden a diferentes casuísticas. En este trabajo exploratorio concluimos que las mujeres aportan el 44\% de los videos (56 piezas en total) frente al 56\% del total, que han sido subidos por hombres (71 piezas). Ahora bien, en necesario establecer, en primer lugar, que existen diferencias entre los géneros (volumen de participación, relevancia de los vídeos, número de visualizaciones, tipos de contenidos subidos, esfuerzo creativo... ) para poder seguir investigando sobre las causas que provocan estas diferencias.

El trabajo ha constatado que existe una expansión transmedial de la promoción de la ficción en Internet, que viene dada por la actividad contributiva de los propis fans de la ficción. Esta conclusión fundamental, amplia conclusiones anteriores respecto al alcance de la actividad transmedial alrededor de la ficción televisiva española, que afirmaban que: "las teleseries en España (... ) manifiestan una considerable promiscuidad transmedial, pero una muy limitada expansión narrativamente transmedial, al menos desde la iniciativa de la corporación mediática" (Rodríguez, Ortiz y Sáez, 2014). Se ha verificado que el feedback de los fans es un recurso transmedial presente, activo y dinámico, capaz de generar audiencia y de contribuir a la promoción de la propia ficción y que merece ser estudiado en los estudios transmediales puesto que amplía el alance de "expansión narrativamente transmedial" de los propios medios de comunicación. Ahora bien, la segunda pregunta de investigación muestra que la categoría "imágenes originales de la serie" sea la que más vídeos registra (69) de 127 indica que el 52\% de 
los fans optan por "cortar" y subir escenas de la serie sin aportar mayor expansión a la ficción mientras que las fans aportan más creatividad en la videocreación.

La ficción televisiva, caracterizada por la serialidad, es uno de los productos culturales televisivos que más pie da al desarrollo de lógicas transmediáticas a través de los recursos digitales. Como afirma Rodríguez (2014): "es precisamente la circunstancia de la serialidad la que garantiza una implicación a largo plazo del espectador," puesto que la prolongación de la narración y la intriga que genera en los públicos resulta complicada de mantener en otros medios (Rodríguez, 2014 citando a Askwith, 2007; Smith, 2009; Evans, 2008, 2011). La fidelidad de la comunidad fan a esa serialidad intrínseca al producto televisivo de ficción, ha sufrido una revolución con la consolidación de Internet como medio de medios. Y es que no solo se ha conseguido consagrar comunidades fandom (Jenkins (2009) y otras agrupaciones online alrededor de las ficciones televisivas, sino que además, como se ha podido comprobar, los propios fans se han convertido en los prescriptores más fieles, los prosumidores más activos y los mejores generadores de paratextos promocionales para la ficción.

No obstante, aunque la importancia del fan-prosumer digital para la promoción de las ficciones televisivas ha quedado patente, hemos podido observar que existen diferencias fundamentales entre la implicación y el tipo de contenido que aportan hombres y mujeres a la promoción de la ficción

Si hacemos referencia a la imagen de la mujer representada en los videos subidos por los fans, destacamos que no existe aparentemente una intencionalidad por parte de la comunidad fan a la hora de dotar de un protagonismo mayor a los sujetos en función del género. En ese sentido podemos afirmar que los fans trabajan los contenidos promocionales alrededor de la ficción centrándose en el interés suscitado por las propias tramas narrativas y que, tal y como arrojan los resultados de nuestro estudio, la expansión del universo transmedial no lleva implícito amago alguno de construcción social de los sujetos protagonistas.

En cualquier caso, el estudio nos plantea nuevas preguntas que merecen un estudio al respecto acerca de las consecuencias de esta promoción fanática en Internet, las implicaciones que tiene, cómo se deriva esta actividad en términos económicos frente a la ficción. Además, se plantea la necesidad de un nuevo estudio, desde un punto teórico de la comunicación que ahonde en el papel del usuario como generador de contenido promocional, creador de nuevas narrativas transmediales y multimediales que forman parte de conglomerado narrativo de la propia ficción ¿estamos ante un nuevo tipo de fan? ¿el nuevo fan-prosumer?

\section{Notas}

1. Los datos respectivos al share y los espectadores son una elaboración propia a partir de la información extraída de Formulatv.com

2. https://www.youtube.com/watch?v=WTHN_XjJBk 


\section{Bibliografía}

Askwith, I. (2007). Tdevision 20: ReconeptualizingTV as an engagement medium [Versión de Massachusetts Institute of Technology Master's Thesis, Cambridge]. Disponible en: http:/ / cms.mit. edu/ research/ theses/ IvanA skwith2007.pdf] (Consulta: 13-02- 2015)

Barthes, R. (2002). Assaigs Cńtics Barcelona: Seix Barral.

Baym, N. (1998). Talking About Soaps: Communication Practices in a ComputerMediated Culture. En Cheryl H. y Alison A. (comps.). TheerizingFandom Fans, SubaltureandIdantity. New York: Hampton Press.

Beeson, M. (2005). Cross-Media Nanative Disponible en http:/ / ncca.bournemouth.ac.uk/ gallery/ files/innovations/2005/Beeson_Michael 45/mbees on innovations.doc (Consulta: 14-02- 2015).

Borrelli, D. (2008). Il mandbdesiamn Peruna socidoǵa da meelia eda lingragg digtali. Napoles: Linguori Editori.

Campos Freire, F. (2008). Las redes sociales trastocan los modelos de los medios de comunicación tradicionales. Rexista Latima deCommicaión Scaial, 63, 287 -293.

Costa-Sánchez, C.; Pĩneiro-O tero, T. (2012). ¿Espectadores o creadores? El empleo de las tecnologías creativas por los seguidores de las series españolas. ComunicaçãoeScaięade, 22, 184204. (http:// goo.gl/ 5NR83e) (Consulta 27-03-2015).

D avidson, D . (2008). Stariesinbetweer namatives andmediums play. ETC Press Creative commons. Disponible en: http:// www.feedbooks.com/ userbook/ 2302/ stories-inbetween-narratives-andmediums-play (Consulta: 16-02-2015)

Davis, S. M. (1987). Futureperfect. Massachusetts: Addison-Wesley publishing company.

D eloitte (2012). Tecnología, medios de comunicación y telecomunicaciones Predicciones 2012. Deloite (online) disponible en:

http:/ / www2.deloitte.com/ content/ dam/ D eloitte/ uy/ D ocuments/ Industrias/ Es_TMT_Trends 2012.pdf

Evans, E (2011). Transmedia tdeisión Audiene, newmedia and dailylife Londres: Routledge.

Ferreras, E. M. (2011). La estrategia de la corporación EITB (Euskal Irratia Telebista) en Facebook y Twitter. Razón y palabra, 76. Disponible en: 
http:/ / www.razonypalabra.org.mx/ N/ N76/ varia/4a\%20entrega/ 36 Ferreras_V76.pdf (Consulta: 15-02- 2015)

Fiske, John (1992). The cultural Economy of fandom. En: AdoringAudience fan altureandpopular media New Y ork: Routledge, Chapman and Hall.

Freitas, C. y Castro, C. (2010). Narrativas audiovisuales y tecnologías interactivas. Reista Estudios Culturales 5,19-42.

García, N. Y Martínez, L. (2009). La representación positiva de la imagen de las mujeres en los medios. Commicar, 16 (32), 209-214.

Gavelas Barroso J.A. (2005). Televisión y adolescentes: una mítica y controvertida relación. Reista Commicar. Reuista deetífica ibercamericana decomnicadón yeducadón, 25, 137-146.

Gerbner, G., (1980). Children and power on television: the other side of the picture. En G erbner, G., Ross, CJ. Y Zigler, E. (Eds.). ChildAbuse an agenda for adion New Y ork: Oxford University Press.

Glascock, J. (2001). G ender roles on primetime network television: D emographics and behaviours. Jaumal of Broadasting\& EletronicMedia, 45, 656-669.

Grandio, M.M. (2009). Audienia, fenómenofanyfición tdeisiva. El casodeFriends Buenos Aires: Libros en Red.

Guerrero, E. (2011). El multisistema plataforma de los grupos televisivos españoles: los formatos de entretenimiento. Reista commicaány hombre 7, 84-101.

Guerrero, M. (2012). La red enmarañada: narrativa transmedia en ficción femenina. El caso de Infidels y Mistresses. Reiista Sigopensamiento 61(31).

González-Alarcón, S. y Anyó Sayol, L. (2009). Experiencia fan en la cultura digital: el caso de Perdidos. ReistaTńpodos 1, 407-413.

Guarinos, V. (2009). Fenómenos televisivos «teenagers»: prototipias adolescentes en series vistas en España. Reista Commicar, 33(17), 203-211.

Guarinos, V., G ordillo, I., Ramírez A. (2010). Masculinidades de ficción televisiva y retroalimentación online. Jóvenes y adolescentes en-red-ados fuera y dentro de Física o química y 
El internado .Actas II CongesoIntemacional delaAsociaciónEspañda deInnestigadares dela

Commicacón (AE-IC): Commicacóny desamolloenla era digtal.

Hernández Pérez, M. y Grandío Pérez, M. (2011). Narrativa crossmedia en el discurso televisivo de Ciencia Ficción. Estudio de Battlestar G alactica (2003-2010). Área abieta, 28, 1-20.

Horkheimer, M. y Adorno, T. (1969). Dialética dd iluminismo Buenos Aires: Sur.

Islas Carmona, J.O . (2008). El prosumidor. El actor comunicativo de la sociedad de la ubicuidad. Palabra Clave, 11, 29.-39.

Jenkins, H. (2006). ConergeneCulture WhereNewandOldMeelia Cdlide New York: New Y ork U.P. (2009): Fans, blogueosyvideguegss La ailtura dela cdabaracón Barcelona: Paidós. (2010): Transmedia Storytelling and Entertainment: An annotated syllabus. Continum Jaumal of Media \& Cultural StudiesV 24(6), 943-958.

Lauzen, MM; D ozier, D M. y Horan, N (2008). Constructing gender stereotypes through social roles in prime-time television. Jaumal of Broadkasting\&EEletronicMeelia, 52 (2), 200-214.

Lacalle, Ch. (D ir) (2010). “Il dibattito sulla rete: dall'individuo isolato all'occhio del G rande

Fratello". Quadamo di Commicazione Rivista di Dialog tra Cultura, 11, 65-78. (2011). La ficción interactiva: televisión y web 2.0 ReistaÁMBITOS, 20. 87-113. (Ed.) (2013). Jónenesy fición tdeisiva: Construxción deidantidady transmedialidad. Barcelona: UOC Press

del telespectador en los medios audiovisuales: de homo-spectador a homo-civis. Reista Iconol4, 8,(1), 147-163.

Sandoval, M. (2006). Sobre el comportamiento de las audiencias jóvenes desde la perspectiva de la convergencia y de las prácticas culturales. Univ.Pshyod, 5, 205-222. 
Scolari, C.A. (2009). Transmedia Storytelling: Implicit Consumers, Narrative Worlds, and Branding in Contemporary Media Production. Intemational Jamal of Communication3, 586-606. (2013). Namativas Transmeelia: aandbtobslosmeelos auetan Barcelona: D eusto.

Scolari, C., Jiménez, M. y Guerrero, M. (2012). Transmedia Storytelling in Spain: four fictions searching for their cross-media destiny. Communication \& Socidy25(1), 137-164.

Scolari, C.A. et al. (2012). Narrativas transmediáticas, convergencia audiovisual y nuevas estrategias de comunicación. Quadamsdd CAC, 38, XV (1), 79-89.

Tognazzi D rake, A. (2012). Las transformaciones de los contenidos audiovisuales y la influencia de los dispositivos móviles en el nuevo escenario transmedia Anàlis: Quadamsdecammicacói altura Núm monogràfico., 81-95.

Tous Rovirosa, A. y D íaz Noci, J. (2009). Estratègies d'interactivitat i ficció televisiva: anàlisi comparada de pàgines webs de sèries de prime time. ReiistaTńpodbs 2, número extra, 1081-1091.

Victoria, J.S. y Arjona, J.B. (2009). La comunicación social de los nuevos canales audiovisuales en Internet: WebTv. Revista Icomo14, 7, 2, 56-74.

Wright, Ch. (1960). "Functional Analysis and Mass Communication”. PublicOpinionQuartdy, 24(4), 605-620.

Wiener, N. (1958). Cibeméticay soaiedad Buenos Aires: Editorial Sudamericana. 


\section{(c) (i) (2) \\ Licencia Creative Commons \\ Miguel Hernández Communication Journal \\ mhcj.es}

\section{Forma de citar este artículo en las bibliografías}

Tatiana Hidalgo Marí y Candelaria Sánchez Olmos (2015): “Las series españolas en YouTube: comparativa de género sobre el fenómeno fan", en Miguel Hernández Communication Journal, no6, páginas 219 a 240. Universidad Miguel Hernández, UMH (Elche-Alicante). Recuperado el de de 20 de: [link del artículo en mhjournal.org] 